\title{
Guía hemerográfica de El Correo del Perú (1871-1878) \\ Primera Parte
}

\author{
Alejandro César Valenzuela Landa \\ Departamento Académico de Literatura
}

A.B. Y V.

1. "Pablo y Virginia". Año VII. 9 de setiembre de 1877, N XXXVI; p. 288. (Poesía).

2. "A un pensamiento", No XXXVI; p. 288. (Poesía).

A.C.

3. "La unión de la fuerza". Año V. 24 de octubre de 1875, N XLIII; p. 343. (Poesía).

4. "El amor de un ángel". 18 de marzo de 1877, № XI; pp. 84-85. (Relato).

A.C. y V.

\section{Biblioteca de Letras}

5. "El último suspiro de una flor". Año VII. 16 de setiembre de 1877 , № XXXVII; p. 296. (Poesía).

A. DE M.

6. “Al trabajo". Año V. 24 de enero de 1875, N² IV; p. 31. (Poesía). A.E.

7. "El mar". Año VII. 4 de marzo de 1877, № IX; p. 70. (Poesía). A.F.A.

8. "A Aurelia". Año VII. 14 de octubre de 1877 , № XLI; p. 327. (Poesía). 
A.H.V.

9. “Tus labios y tus ojos". Año V. 9 de mayo de 1875, № XIX; p. 151. (Poesía).

A.J.D.

10. “¿Sería así?”. Año VII. 29 de abril de 1877, NN$^{2}$ XVII; p. 132. (Artículo).

11. “Órdenes militares". Año VII. 6 de mayo de 1877, № XVIII; pp. 141-142. (Artículo).

A.L.F.

12. "El cura de Cucañari”. Año V. 14 de marzo de 1875, № XI; pp. 82-83. (Relato).

A.M.C.

13. "A un billete de Banco". Año V. 3 de enero de 1875, № I; p. 3. (Poesía).

A.M.T.

14. “En un álbum”. Âñ VI. 30 de julio de 1876, № XXXI; 248. (Poesía).

15. "El verbo apretar". Año VII. 11 de febrero de 1877, № VII; p. 56. (Poesía). Biblioteca de Letras

A.P.S. "Jorge Puccinelli Converso"

16. “Charada". Año IV. 6 de diciembre de 1874, N XLIX; p. 390.

A.R.

17. “Dos retratos". Año V. 1 de agosto de 1875, NN2 XXXI; p. 247. (Poesía).

A.S.

18. “Arpegios”. Año VIII. 2a. época. 29 de junio de 1878, № 12; p. 96. (Poesía).

A. X.

19. “Conversación”. Año IV. 11 de octubre de 1874, N² XLI; p. 325. (Artículo). 
ABATE PRÉVOST

20. Vide: Manuel María Seguín (traductor).

ABELARDO

21. "Pobre flor". Año VI. 6 de agosto de 1876, NN XXXII; p. 253. (Poesía).

ABEN-XOAR

22. "Mariana". Año IV. 21 de junio de 1874, № XXV; p. 196. (Poesía).

23. "La fruta del cercado ajeno". Año IV. 19 de julio de $1874, \mathrm{~N}^{2}$ XXIX; p. 230. (Poesía).

24. “Mesa revuelta". Año IV. 26 de julio de 1874, № XXX; pp. 238 239. (Artículo humorístico).

25. "Mesa revuelta". Año IV. 16 de agosto de 1874, N XXXIII; pp. 262-263. (Artículo humorístico).

26. "Apariencias y realidades". Año IV. 27 de setiembre de 1874, № XXXIX; p. 308. (Artículo humorístico).

27. "Mesa revuelta". Ârio IV. 27 de setiembre de 1874, № XXXIX; pp. 310-311. (Artículo humorístico).

28. "El mundo al revés". Año IV. 11 de octubre de 1874, № XLI; pp. 326-327. (Artículo humorístico).

29. "Mesa revuelta": Año IV 18 de octubre de 1874, № XLII; pp. 334-335. (Artículo humorístico).

30. "Camino del infierno". Año V. 25 de abril de $1875, \mathrm{~N}^{2}$ XVII; pp. 130-131. (Relato).

31. "Un sabio". Año V. 20 de junio de 1875, N XXV; p. 200. (Artículo humorístico).

32. "Un aristócrata". Año V. 10 de octubre de $1875, \mathrm{~N}^{2}$ XLI; p. 328329. (Relato).

ACUÑA, Manuel

33. "Cinco de mayo". Año V. 7 de noviembre de 1875, No XLV; p. 360. /Al aniversario de la batalla de Puebla/ (Relato).

ACUÑA Y VILLANUEVA, Rosario

34. "A la fe". Año VII. 4 de febrero de 1877 , № V; p. 36. (Artículo). 
ADAM

35. "Las últimas horas de un crítico". Año V. 18 de abril de $1875, \mathrm{~N}^{2}$ XVI; p. 125. (Relato).

ADRIANA

36. "Simpatía a la excelente poetisa limeña Leonor Saury". Año II. 30 de marzo de 1872, № XIII; pp. 100-101. (Poesía).

37. "Desvelos". Año III. 8 de marzo de 1873, № X; p. 75. (Poesía).

38. "El homicida" Año III. 15 de marzo de $1873, \mathrm{~N}^{2} \mathrm{XI}$; p. 87.

39. “Merecido". Año III. 22 de marzo de 1873, № XII; p. 94. (Poesía).

40. “Al Chico Terencio". Año III. 5 de abril de 1875, № XIV; p. 110. (Poesía).

41. “Su imagen”. Año III. 12 de abril de 1873, № XV; p. 119. (Poesía).

42. “Ruido que espanta". Año III. 19 de abril de 1873, N XVI; p. 127. (Poesía).

43. "Mi corazón". Año III. 26 de abril de 1873, N XVIII; p. 134. / Traducido de Entique Heine [sic]/(Poesía).

44. "Gotas de llano". Año III 3 de mayo de 1873, NN$^{2}$ XVIII; p. 143. (Poesía).

45. "Sonrisas y llanto", Año III. 10 de mayo de 1873, № XIX; pp. 150-151. (Poesía).

46. "Dos coronas del cristianismo". Año III. 7 de junio de 1873 , No XXIII; p. 182. (Poesía).a de Ietras

47. “Amor de madre". Año HI: 14 dejunio de ,1873, No XXIV; p. 191. (Poesía).

48. “¡Felipe Pardo!”. Año III. 12 de julio de 1873, N² XXVIII; p. 222. (Poesía).

AGAR

49. "La cartera de mi compadre". Año V. 29 de agosto de 1875 , № XXXV; pp. 283-284. (Relato).

50. "Al gallo que canta le aprietan la garganta". Año V. 10 de octubre de 1875, N XLI; pp. 329-330. (Relato).

51. "Ir por lana y salir trasquilado". Año V. 28 de noviembre de 1875 , $\mathrm{N}^{2}$ XLVIII; pp. 386-387. (Relato).

52. ' "Sin amor y sin dinero". Año VI. 12 de marzo de 1876, № XI; pp. 83-84. (Artículo).

53. "El maestro Dieguillo". Año VI. 2 de abril de 1876, № XIV; pp. 107-108. (Relato). 
54. "Los borrachos no medran". Año VI. 16 de abril de 1876, $\mathrm{N}^{2}$ XVI; pp. 123-124.

55. "La muchacha Dorila". Año VI. 30 de abril de 1876, N² XVIII; pp. 142-144. (Relato).

56. “El sargento Roldán”. Año VI. 21 de mayo de 1876, № XXI; pp. 164-165. (Artículo).

57. "El Bachiller Sarmientos". Año VI. 25 de junio de 1876, № XXVI; pp. 205-207. (Artículo).

58. "La mendiga". Año VI. 11 de junio de 1876, № XXIV; pp. 186188. (Relato).

59. "La moza mala". Año VI. 16 de julio de 1876, № XXIX; pp. 229232. (Relato).

60. “La moza mala". Año VI. 23 de julio de 1876, N XXX; pp. [233]236. (Relato).

61. “Es el culantro hervir, hervir?”. Año VI. 27 de agosto de 1876, $\mathrm{N}^{2} \mathrm{XXXV}$; pp. 276-280. (Relato).

62. "El médico Zandajuelo". Año VI. 24 de setiembre de 1876, № XXXIX; pp. 306-308. (Relato)

AGRICULTOR PERUANO

63. "Inmigrantes asiáticos,.- Año VI. 19 de noviembre de 1876, № XLVII; pp. 373-374. (Artículo).

aguirre vargas, Bicente teca de Letras

64. “Por sospéchas'? Año Vir. 16 desetiembre de 1877, № XXXVIII; pp. 295-296. (Relato).

ALAH

65. "Un golpe a tiempo". Año IV. 11 de octubre de 1874. N² XLI; p. 323. (Artículo).

ALCÁNTARA, Joaquín Asencio

66. "Albores y crepúsculos". Año V. 19 de setiembre de $1875, \mathrm{~N}^{2}$ XXXVIII; p. 307. (Poesía).

ALARCón, P[edro] A[ntonio] de, (Español, 1833-1891)

$6 \%$. "Amor eterno". Año V. 11 de julio de 1875, № XXVIII; p. 228. (Poesía). 
68. "En el álbum de Consuelo". Año VI. 30 de enero de 1876, № V; p. 36. (Poesía).

\section{ALBISTUR, Jacinto}

69. "A la eminente artista Esmeralda Cervantes o lo que es lo mismo a la señorita Clotilde Serdá y Bosch". Año VI. 30 de enero de 1876, № V; p. 40. (Poesía).

ALEGRÍA, Antonio

70. "A la pirámide de Cholula". Año VI. 2 de enero de 1876, № I; p. 5. (Poesía).

71. "El día y la noche". Año VI. 11 de junio de 1876, № XXIV; pp. 191-192. (Poesía).

ALEMÁN, Ignacio

72. "El entierro o funeral". Año VI. 7 de mayo de 1876, N ${ }^{2}$ XIX; pp. [145]-147. (Artículo).

ALEMPARTE, J.A.

73. "Verdades amargas". Año VI. 13 de febrero de 1876, № VII; p. 54.

ALI

74. "Panchito a Pancho" Año II 27 de-abril de 1872, № XVII, pp. 131-132. TCartas de un joven trasandino [sic]/ (Artículo).

75. "Panchito " Pancho". Ano II. 4 de mayo de 1872, № XVIII; p. 139. (Artículo).

76. "Panchito". Año II, 25 de mayo de 1872, N² XXI; pp. 164-165. (Artículo).

\section{ALMANZOR}

77. “A la señorita Leonor Sauri". Año IV. 19 de abril de 1874, N XVI; p. 124. (Poesía).

78. "Solución a la charada publicada en el número anterior". Año IV. 13 de diciembre de 1874, N² L; p. 399.

79. “Gratitud". Año V. 22 de agosto de 1875, N XXXIV; p. 271. (Poesía).

80. “Sin nombre". Año VI. 5 de marzo de 1876, No X; pp. 76-78. (Artículo). 
ALVAREZ, Enrique

81. "Los pedantes". Año V. 17 de enero de 1875, № III; p. 22. (Artículo).

82. "El tahur". Año V. 29 de agosto de 1875, N XXXV; p. 283. (Artículo).

83. "La inmortalidad". Año VIII, 14 de abril de 1878, $\mathrm{N}^{2} \mathrm{XV}$; p. 120. (Artículo).

ALVAREZ DE AZEVEDO

84. "De la incredulidad en Byron, Shelley, Voltaire y Musset". Año IV. 1 de noviembre de 1874 , № XLIV; p. 347. (Artículo).

ALONSO, Salvador

85. "La felicidad". Año VI. 30 de enero de 1876, No V; pp. 39-40. (Artículo).

ALZAMORA, Elías

86. “El poeta”. Año VII. 4 de noviembre de 1877 , № XLIV; p. 351. (Artículo).

AMÉZAGA, A.

87. "El secreto de la felicidad". Año III. 31 de diciembre de 1873, Número Extraordinario, Tomo III; p. X. (Artículo).

AMÉzAGA, Juana R[osa] de (1853-1904) Letras

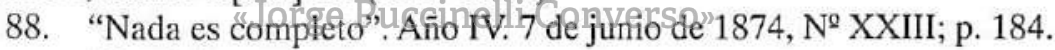
(Poesía).

89. "El Señor del mar". Año IV. 15 de noviembre de 1874, № XLVI; p. 367. (Artículo).

90. "Sueños, ilusiones y pensamientos". Año IV. 13 de diciembre de 1874 , № L; p. 399. /Aparece bajo el epígrafe de 'Reproducciones Nacionales'/ (Artículo).

91. "La belleza". Año IV. 31 de diciembre de 1874, Número Extraordinario. Tomo IV; pp. XXV-XXVI. (Artículo).

92. "Apariencias y realidades". Año V. 26 de diciembre de 1875, Número Extraordinario, Tomo V; p. X. (Poesía).

AMÉZAGA, M[ariano] (1834-1894)

93. “La vocación". Año VII. 11 de febrero de 1877, № VII; p. 53. (Artículo). 
94. "El libre albedrío". 1872. Número Extraordinario para Exposición Nacional; pp. IX-X. (Artículo).

95. "Decepción". Año IV. 31 de diciembre de 1874, Tomo IV; p. XVII. (Poesía).

96. “Al despertar". Año V. 8 de agosto de 1875, N XXXII; p. 260. (Poesía).

97. “¡No hay miedo!”. Año V. 26 de diciembre de 1875, Número Extraordinario, Tomo V; pp. XXXIX-XL. (Poesía).

AMUNÁTEGUI, Manuel (chileno 1802-1886)

98. "La leva de los indios". Año II. 1 de julio de 1872, Número Extraordinario para la Exposición Nacional; p. XXI. (Artículo).

AMUNÁTEGUI, Miguel Luis

99. "Los dos amores". Año IV. 20 de diciembre de 1874, № LI; pp. 402-404. (Tradición).

100. "El padre Bardesi"' Año V. 14 de febrero de 1875, N VII; pp. $53-$ 54. (Artículo).

101. "Un amigo inseparable". Año V. 28 de febrero de 1875, № IX; pp. 67-69. (Tradición).

102. "Por ser cristiano". Año V. 12 de diciembre de 1875 , № L; pp. 402-403. (Artículo).

103. "Una muję que notescupió nuñca"..Año VI. 27 de febrero de 1876, No IXjpp 69-71.(Tradición).

ANA

104. “Al señor M.”. Año IV. 16 de agosto de $1874, \mathrm{~N}^{2}$ XXXIII; p. 260, [Respuesta al poema “¡Viva la reina!”, firmado por M.]. (Poesía).

ANDRADE, Olegario V[íctor] (Argentino, 1839-1882)

105. "La vuelta del hogar". Año VI. 27 de febrero de 1876, $N^{2}$ IX; p. 27. (Poesía).

106. "El nido de los cóndores". Año VII. 30 de setiembre de $1877, N^{0}$ XXXIX; pp. 311-312. (Poesía).

ANGUITA, Adela

107. “A un niño". Año IV. 29 de noviembre de 1874, № XLVIII; p. 378. (Poesía). 
108. “¡Yo te bendigo!”. Año V. 4 de abril de 1875, N XIV; p. 109. (Poesía).

109. "El luto del corazón". Año VI. 2 de abril de 1876, № XIV; pp. [105]-106. (Relato).

ANGULO, J[osé] C[amilo] (n. en Moquegua, 1832-?)

110. "Pensamientos a Genoveva". Año III. 31 de diciembre de 1873, Número Extraordinario, Tomo III; p. XXVIII. (Poesía).

111. "A la Sra. J.G. de B." Año IV. 31 de diciembre de 1874, Número Extraordinario, Tomo IV; p. XXV. (Poesía).

112. "La tierra natal". Año V. 8 de agosto de 1875 , N XXXI; pp. 256257. (Poesía).

113. "La esperanza". Año V. 26 de diciembre de 1875, Número Extraordinario, Tomo V; pp. XXVII-XXVIII. (Poesía).

114. "Insomnio". Año VI. 16 de abril de 1876, № XVI; pp. 127-128. (A T.M. Pérez). (Poesía).

115. "El pensamiento". Año VI. 28 de mayo de 1876, № XXII; p. 172. (Poesía).

ANÓNIMO

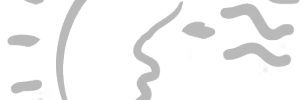

116. “Nurerdin-Kan”. Año II 27 de enero de 1872, № IV; pp. 29-30. /Cap. primero/. (Novela).

117. “Nurerlin-Kan”. Año II. 3 de febrero de 1872, № V; p. 37. /Cap. II/.

118. Ídem. Año Mrgio decfebreto de $1872, \mathrm{SN}^{2}$ VI; pp. 45-46.

119. Ídem. Año II. 17 de febrero de 1872, N VII; pp. 53-54. /Cap. III/.

120. Ídem. Año II. 24 de febrero de 1872 , N² VIII; p. 61. /Cap. IV/.

121. Ídem. Año II. 2 de marzo de 1872, N IX; p. 69. /Cap. V/.

122. Ídem. Año II. 9 de marzo de 1872, N X; p. 78. /Cap. VI/.

123. Ídem. Año II. 13 de abril de 1872, № XV; pp. 117-118.

124. Ídem. Año II. 20 de abril de 1872, No XVI; pp. 125-126. /Cap. XI/

125. Ídem. Año II. 27 de abril de 1872, № XVII; pp. 133-134. /Cap. XII/.

126. Ídem. Año II. 23 de marzo de 1872, N XII; pp. 92-93. /Cap. VII/.

127. Ídem. Año II. 30 de marzo de 1872 , № XIII; p. 101. /Cap. VIII/.

128. Ídem. Año II. 6 de abril de 1872, N XIV; pp. 109-110. /Cap. IX/.

129. Ídem. Año II. 4 de mayo de 1872 , No XVIII; p. 142.

130. Ídem. Año II. 11 de mayo de 1872, N XIX; pp. 150-151.

131. Ídem. Año II. 18 de mayo de 1872 , N XX; pp. 158-159. 
132. Ídem. Año II. 25 de mayo de 1872, № XXI; pp. 166-167. /Cap. $\mathrm{XV} /$.

133. Ídem. Año II. 1 de junio de 1872, № XXII; pp. 174-175.

134. Ídem. Año II. 8 de junio de 1872, № XXIII; pp. 182-183. /Cap. $\mathrm{XVI} /$.

135. Ídem. Año II. 15 de junio de 1872, № XXIV; p. 190.

136. Ídem. Año II. 22 de junio de 1872, № XXV; pp. 198-199.

137. Ídem. Año II. 6 de julio de 1872, № XXVI; pp. 205-206.

138. Ídem. Año II. 13 de julio de 1872, № XXVII; pp. 213-214. /Cap. $\mathrm{XIX} /$.

139. Ídem. Año II. 20 de julio de 1872, № XXVIII; pp. 221-222. /Cap. $\mathrm{XX} /$.

140. Ídem. Año II. 27 de julio de 1872, № XXIX; p. 230. /Cap. XXI/

141 "El alma nunca envejece". Año II. 21 de diciembre de 1872, № L; p. 396. [Artículo tomado del Museo Ilustrado].

142. "Epigrama". Año II. 30 de marzo de 1872, № XIII; p. 100. (Poesía).,

143. "La noche". Año II. 21 dé diciembre de 1872, № L; p. 397. [Artículo tomado del Mundo Ilustrado].

144. “Zape!”. Año III, 26 de julio de 1873, № XXX; p. 242. (Poesía).

145. "El tiempo y la cuenta". Año III. 16 de agosto 1873, $\mathrm{N}^{2}$ XXXIII; p. 267. (Poesía).

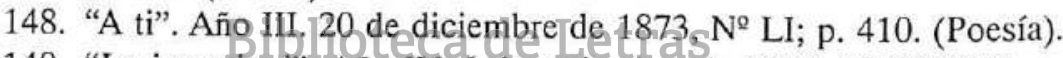

149. "La ingratitud". Ano IV. 6 de setiembre de 1874, № XXXVI; p. 283. (Cuentorgen verso).

150. "Dos bellezas". Año VII. 24 de junio de 1877, № XXV; p. 200. (Poesía).

185. "El juicio de Salomón". Año VI. 18 de junio de 1876, № XXV; p. 198. (Artículo).

186. "Juan Jouvenet". Año VII. 11 de marzo de 1877, № X; p. 78. [Rasgos biográficos].

\section{ARSENIO}

187. "Ombra et nihil". Año IV. 12 de julio de 1874, № XXVIII; pp. 219-220. (Poesía).

ARTEAGA ALEMPARTE, Justo

188. "Una verdad sobre el hombre". Año VI. 13 de febrero de $1876, \mathrm{~N}^{Q}$ VII; p. 52. (Artículo). 
189. "Pobreza y riqueza". Año VI. 13 de febrero de 1876, $\mathrm{N}^{2}$ VII; pp. 52-53. (Artículo).

190. "La embriaguez". Año VIII. 21 de abril de 1878, N XVI; pp. 126127. (Artículo).

191. "La ausencia". Año IV. 11 octubre de 1874, NN 1874, N XLI; pp. 324-325. (Artículo).

ARZOLA, Ramón

192. “¿Por qué no cantas?”. Año IV. 23 de agosto de 1874, № XXXIV; p. 270. (Poesía).

193. "La oración". Año IV. 30 de agosto de 1874, № XXXV; p. 276. (Poesía).

194. "En el silencio". Año IV. 31 de diciembre de 1874, Número Extraordinario, Tomo IV; p. XL. /Dedicado a Leonor Saury/ (Poesía).

ASTAROT

195. "El demonio comerciante", Año V. 11 de julio de $1875, N^{2}$ XXVIII; p. 222. (Artículo).

196. "Niñas, jamonas y viejas". Año VI. 7 de mayo de $1876, \mathrm{~N}^{2}$ XIX; pp. 147-148. (Artículo humorístico).

ASTUDILLO, Amador

197. "Un drama en el Pacifiço". Año VI. 11 de junio de 1876 , № XXIV; pp. 190-191. (Artículo).

AZA, Vital (Español, 1851-1912)

198. “¡Recuerdos!”. Año IV. 4 de octubre de 1874, № XL; pp. 318-319. (Poesía).

AZPURU, R.

199. "La espada de Ayacucho". Año V. 23 de febrero de 1875, № IX; p. 67. (Artículo).

B.G.U,

200. "Al sol del Perú. En el aniversario de la Independencia". Año VI. 30 de julio de 1876, № XXXI; pp. 244-245. /Oda a Pedro José Calderón/ (Poesía). 
BACHILLER, Antonio

201. "El dorado". Año V. 24 de enero de 1875 , NN IV; p. 27. (Artículo).

BACHILLER Y MORALES, A.

202. "El capitán Diaguillo". Año VI. 27 de febrero de 1876, № IX; p. 69. (Leyenda cubana).

BALMASEDA, F[rancisco] J[avier]

203. "El elefante y las hormigas". Año V. 29 de agosto de $1875, \mathrm{~N}^{2}$ XXII; pp. 282-283. (Fábula).

204. "Carlos Manuel de Céspedes". Año V. 24 de octubre de 1875, № XLIII; pp. 344-345. [Rasgos biográficos].

205. "Cuba". Año VII. 20 de mayo de 1877, № XX; pp. 154-155. (Poesía).

BALLÉN, L.

206. "A unos cabellos negros". Año IV. 31 de diciembre de 1874, Tomo IV; p. XL. (Poesía).

BALLESTEROS, José Ramón (Traductor)

207. "El cuervo". Año IV. 9 de agosto de $1874, \mathrm{~N}^{2}$ XXXII; p. 251. /Traducción del poema de E.A. Poe/.

BANFI, Félix

\section{Biblioteca de Letras}

208. Carta a don Federico Long. Año III. 20 de diciembre de 1873, No LI; p. 409. [Sobre sanciones de la Inquisición].

BAÑADOS ESPINOZA, Julio

209. "Sara". Año VIII. 7 de abril de 1878, N XIV; pp. 111-112. (Leyenda americana).

BARALT, Rafael M.

210. "Idilios". Año VII. 11 de marzo de 1877, No X; pp. 79-80. (Artículo).

211. "Lo que es ella para mí". Año VIII. 2a. época. 25 de julio de 1878 , $\mathrm{N}^{2} 34$; p. 270. (Poesía). 


\section{BARBIERI, Bárbaro}

212. "Etapas de las privanzas". Año IV. 18 de octubre de 1874 , No XLII; pp. 333-334. /Aparece bajo el epígrafe de 'Reproducciones Nacionales'/ (Artículo).

BARONESA DE WILSON (La)

213. "La literatura y la mujer". Año V. 26 de diciembre de 1875, Número Extraordinario, Tomo V; pp. VI-VII. (Artículo).

214. "La ascención del Señor". Año VI. 16 de abril de 1876, № XVI; p. [121] (Poesía).

215. "La semana". Año VIII. 2a. época. 17 de junio de $1878, \mathrm{~N}^{2} 3$, pp. 12-13. (Artículo).

216. Ídem. Año VIII, 2a. época. 22 de junio de 1878, N² 7; pp. 52-53. (Artículo).

217. Idem. Año VIII, 2a. época. 28 de junio de $1878, N^{2} 11$; pp. 83 84. (Artículo).

218. Ídem. Año VIII, 2a. época. 6 de julio de 1878, № 18; pp. 140-141. (Artículo).

219. Ídem. Año VIII, 2a. época. 13 de julio de $1878, \mathrm{~N}^{2} 24$; pp. 188 189. (Artículo).

220. Ídem. Año VIII, 2a. época. 19 de julio de 1878, № 29; pp. 236237. (Artículo).

221. Ídem. Año VIH; 2a. época. 27 de julio de 1878, N² 36; pp. 285 286. (Articulo).

222. Ídem. Año vin, Za. épocal 3 de agosto de 1878, № 41; pp. 324325. (Artículo).

223. Ídem. Año VIII, 2a. época. 10 de agosto de 1878 , № 47; pp. 372 373. (Artículo).

BARRANTES, Vicente

224. "A.S.M. El Rey". Año V. 31 de octubre de 1875, № XLIV; pp. 354-355. /Aparece bajo el epígrafe de 'Homenaje Poético' [a Alfonso XII]/ (Poesía).

BARREDA, Rafael

225. "Cría fama y échate a dormir". Año IV. 31 de mayo de 1874 , № XXII; p. 173. (Artículo). 
BARRENECHEA, J[osé] A[ntonio] (1829-1889)

226. "Los intereses materiales y la exposición". Año II. 1 de julio de 1872, Número Extraordinario para la Exposición Nacional; p. XIII. (Artículo).

BARRERA, Pablo M[aría]

227. "Cosas y casos". Año IV. 22 de noviembre de 1874, № XLVII; p. 371. (Poesía).

228. "Mediodía". Año V. 5 de setiembre de 1875, № XXXVI; pp. 288289. (Poesía).

BARRIGA, Juan Agustín

229. "Velada". Año VI. 9 de julio de 1876, № XXVIII; p. 220. (Poesía).

B[ARROS] A[RANA], D[iego] (Chileno, 1830-1907)

230. /Sobre libros peruanos de don Manuel de Odriozola y don Manuel S. Pasapera, prof. de matemáticas/. Año V. 28 de noviembre de 1875, No XLIII; p. [381] (Reseña).

231. "Bibliografía". Año VI. 2 de abril de 1876, N² XIV, pp. 108-109. (Reseña sobre la obra de R. Palma, Tradiciones; Odriozola, Tomo VII. Las tres épocas del Perú, o compendio de su historia // Historia de la Monja Alférez /l Guía del Virreynato de Bs. As. para 1803 y J.T Medina, Memorias del reing de Chile y don Francisco Meneses).

232. "Conquista Qy" población del Perü. Año VII. 17 de junio de 1877 , № XXIV; p. 192. (Artículo).

\section{BARRIOS GREZ, Daniel}

233. "Algo sobre la palabra 'palabra"”. Año VI. 23 de enero de 1876, № IV; p. 33. (Artículo).

234. "El asno cargado". Año VI. 12 de marzo de $1876, \mathrm{M}^{2}$ XI; p. 88. (Fábula).

235. "El rey, el obispo y el bufón". Año VI. 19 de marzo de 1876, № XII; p. 92. (Fábula).

BASADRE, Modesto (Tacna, 1816-1905)

236. Rivagüero [sic]. Año VIII. 2a. época. 28 de julio de 1878, № 37; pp. 291-292. [Rasgos biográficos]. 


\section{BAZ, Gustavo}

237. "Dolora". Año IV. 2 de agosto de 1874, № XXXI; p. 242. (Poesía).

238. "Av...". Año VI. 27 de febrero de 1876, № IX; p. [65]. (Poesía).

\section{BEATRIZ}

239. "Isabel La Católica y Cristóbal Colón". Año II. Lima, 1 de julio de 1872, Número Extraordinario para la Exposición Nacional; pp. XVIII-XIX. (Artículo).

240. "Los asuntos morales son muy delicados". Año IV. 1 de marzo de 1874, № IX; pp. 68-69. [Artículo sobre un aforismo que publicara Juan de Arona].

BECAVER, G.

241. "Rimas". Año V. 9 de mayo de 1875, № XIX; p. 148. (Poesía).

242. "Rimas". Año V. 30 de mayo de 1875, № XXII; pp. 174-175. (Poesía).

243. "Su imagen" [sic]. Año VII. 15 de abril de 1877, N XV; p. 119. (Poesía).

BECERRA, R.

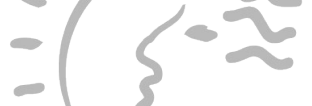

244. "Siempre una ella". Año IV. 31 de diciembre de 1874, Número Extraordinario, Tomo IV; pp. XVIII-XX (Al tradicionista literario Ricardo Palma). (Tradición).

\section{Blblioteca de Letras}

BECERRO DE BENGOA,rge Puccinelli Converso"

245. "La paz de la isla de los faisanes". Año V. 3 de enero de 1875, N2 I; pp. 6-7. (Artículo histórico).

BECQUER, G[ustavo Adolfo] (1836-1870)

246. "Rimas". Año V. 19 de setiembre de 1875, N XXXVIII; p. 304. (Poesía).

247. "Las hojas secas". Año VII. 4 de febrero de $1877, \mathrm{~N}^{2}$ V; pp. 3637. (Leyenda).

248. "Rimas". Año VII. 11 de marzo de 1877, № X; p. 76. (Poesía). 249. "Rimas". Año VII. 18 de marzo de 1877, № XI; p. 86. (Poesía).

250. "Rimas". Año VI. 22 de julio de 1877, No XXIX; p. 232. (Poesía).

251. “¿Es raro!!". Año VII. 12 de agosto de 1877, N XXXIII; pp. 252253. (Leyenda). 
BEGOVICH, Esteban de

252. "La Marsellesa o el canto marcial del ejército del Rhin". Año V. 29 de agosto de $1875, \mathrm{~N}^{2} \mathrm{XXXV}$; p. 280. (Artículo).

\section{BELISA}

253. "La flor de las nieves". Año VI. 4 de junio de 1876, № XXIII; p. 183. (Leyenda).

BELZÚ DE DORADO, Mercedes

254. "Plegaria". Año VI. 11 de junio de 1876, № XXIV; p. 191. (Poesía).

255. "Desaliento". Año VI. 17 de diciembre de 1876, № LI; p. 411. (Poesía).

256. "Recuerdos de amistad". Año VII. 7 de enero de 1877, № I; pp. 6-7 /A Carlos Uriburu de Ruck/ (Poesía).

257. "Gethsemaní". Año VII. 25 de marzo de 1877, № XII; pp. 91-92. (Poesía).

258. "Salmo 136". Año VII. 10 de junio de 1877, N² XXIII; p. 180. (Poesía).

BELLO, Emilio

259. “Oriental”. Año VI. 23 de enero de 1876, № IV; p. 31. (Poesía). BENAVIDES, M[anuei] A[ntonio]

260. "Las nupcias gloriosas". 20 de setiembre" de 1874, № XXXVIII; p. 302. (Poesía).

261. "Tú y yo". Año IV. 15 de marzo de 1874, NN$^{\circ}$ XI; p. 86. (Canción).

262. "Letrilla". Año V. 30 de mayo de 1875, № XXII; p. 176. (Poesía).

263. "Un rayo de luz". Año V. 27 de junio de 1875, № XXVI; p. 212. (Poesía).

264. "Rimas". Año V. 12 de set. de $1875, \mathrm{~N}^{2}$ XXXVII; p. 297. (Poesía).

265. "Antes de partir". Año V. 26 de diciembre de 1875, Número Extraordinario, T. V; p. XXVII. (Poesía).

266. "Para quién son mis versos". Año VII. 11 de marzo de 1877, № X; p. 80. (Poesía).

267. "Una caricia". Año VII. 18 de marzo de 1877, № XI; p. 84. (Poesía).

268. “Por qué lloras?”. № XII, 1877; p. 100. (Poesía).

269. “M.L”. № XV, 1877; p. 166. (Poesía). 
270. "Constantino Carrasco" N XIX, 1877; p. 147. (Poesía).

271. "Deseo". № XX, 1877; 160. (Poesía).

272. "Apólogo". N XXXVIII, 1877; pp. 300-301. (Poesía).

273. "A Lili". NN XVI, 1878, pp. 126-126. (Poesía).

274. "La visión y el poeta". № XVII, 1878, p. 135. (Poesía).

275. "A una de ojos verde". № XX, 1878, p. 156. (Poesía).

276. Reseña sobre una obra El precio de la gloria. Drama en un acto, Valparaíso, 1875/Cf. R.P./

BENJAMÍN DEL $S$.

277. "A la luna". № XXI, 1877, p. 164. (Poesía).

BENOT, Eduardo

278. "La loca de la casa". № XL, 1874, pp. 316-318. (Artículo).

BERNARDO CUS Y AMATT

279. "Himnos a la industria". № XXV, 1875, p. 199.

BERNAT, Pedro A.

280. "La noche de la partida" $\mathrm{N}^{2}$ XVI, 1875, p. 124. (Poesía).

BERTHET, Elle

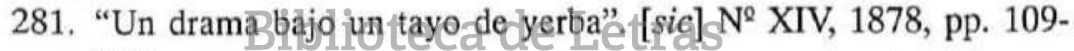
110. «Jorge Puccinelli Converso»

BLANCO CUARTIN, Manuel

282. "Diccionario biográfico americano". $\mathrm{N}^{2} \mathrm{~V}, 1876$; pp. [35-36]. (Artículo).

283. f́dem, NN VI, 1876, pp. 42-43. (Artículo).

BLASCO, Eusebio

284. "La serie". № XLVII, 1874, pp. 371-373. (Cuento).

285. "La telegrafía de España". № XXXII, 1875, pp. 257-258. (Artículo).

BOLOGNESI, María (coautora) Vide: María Teresa SANTILLANA.

BOUFFERS

287. "Epigramas". № XXV, 1874, p. 198. (Poesía). 
BRIAN, Casio

288. "Caridad". № XXV, 1876, p. 200. (Poesía).

BUENDÍA, Adriana

289. "Dulce consuelo". № XLVII, 1874, p. 375. (Poesía).

290. "Querella”. Número Extraordinario, 1874, p. XXIV (Poesía).

291. "Adiós del alma”. N VII, 1875, p. 55. (Poesía).

292. "Débil tributo al señor Almanzor Paz-Soldán, en respuesta a su galante soneto". № X, 1875, p. 76. (Poesía).

293. "Ecos del Rímac". Número Extraordinario, 1875, p. XIV. (Poesía).

294. "Siempreviva". Número Extraordinario, 1875, p. XXV /A Ignacio Novoa/ (Poesía).

295. "Una flor del sepulcro". $\mathrm{N}^{2}$ XXXII, 176, pp. 251-252. /En la muerte de su hermana Amelia/ (Poesía).

296. "Lluvia de perlas". № XXXV, 1876, p. 275. (Poesía).

BUG-JARGAL

297. "La mano de Dios". $\mathrm{N}^{2} \mathrm{XL}, 1874$, p. 316. (Tradición de Lima). [sic].

BURGOS

298. “La Catedral de Burgos". № XXXV, 1875, p. 285. (Artículo).

BUSILIS Y CA. Biblioteca de Ietras

299. “Arroz con pollo”. № 28, 1878, pp. 204-205. (Poesía).

BUSTAMANTE, Ricardo [José] (Boliviano 1821-1884).

300. "Los muertos". № XLVII, 1875, p. 376. (Poesía).

301. "Lágrimas". № XIV, 1876, p. 109. (Poesía).

302. "Oda al gran Mariscal de Ayacucho". № XXII, 1877, p. 173. (Poesía).

303. "Romería". № XXV, 1877, p. 199. (Poesía).

304. "Por un duro, un ciento de versos". № XXXII, 1877, pp. 255-256. (Poesía).

305. "Al círculo literario de La Paz". № XXXIV, 1877, pp. 268-269. (Poesía).

306. “¡Arriba pensadores!”. N² XVIII, 1878, p. 143. (Poesía). 
BUSTAMANTE DE BAEZA, Hortencia

308. "A la felicidad". № XVII, 1876, p. 135. (Poesía).

BUSTILLOS, Eduardo

309. "La hija del poeta". № III, 1875, pp. 22-23. (Poesía).

BUXÓ, Eloy P[erillán] (Español).

310. "La novia del sepulcro". $\mathrm{N}^{\circ}$ XXXVIII, 1877, p. 302. /Trad. del portugués/ (Poesía).

311. "Educación y enseñanza". № XLI, 1877, p. [321] [Aviso ofreciendo sus servicios para la educación].

312. "Carta de Bolivia". N XLVI, 1877, pp. 363-364. (Poesía).

313. "La semana". № XLVI, 1877, p. 368. (Artículo).

314. "Los narcisos". № 3, 1878, 2a. época, p. 23. (Artículo).

315. "La bola de nieve". $\mathrm{N}^{2} 5,1878$, 2a. época, p. 39. (Artículo).

C.

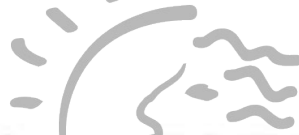

316. "El hambre y la corrupción". No XLV, 1874, pp. 355-356. (Artículo).

216. “Trono". № XVIII, 1874, p. 142. (Poesía).

217. "Consecuencias inevitables". N XXII, 1876, pp. 171-172. (Artículo).

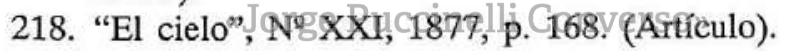

C.A.C.

319. "Igualdad política de ciudadanos naturales y naturalizados". $\mathrm{N}^{2} \mathrm{~V}$, 1877, pp. 34-36. (Artículo).

320. Ídem. No VI, 1877, pp. [45]-46. (Artículo).

321. Ídem. $\mathrm{N}^{2}$ VII, 1877, pp. 54-55. (Artículo).

C.A.R.

322. "A la patita de Eva". N ${ }^{e}$ XVI, 1874, p. 124-125. /A Gustavo de la Fuente/ (Poesía).

C.C.

323. "El gorro del muerto". № XL, 1874, pp. 319.320. (Tradición popular). 
324. "El mono crítico". № XXVI, 1875, p. 211. (Fábula).

C. DE A.

325. "El canto del destierro". N2 XL, 1875, p. 321. (Poesía).

C. DEL L.

326. "La cruz ensangrentada". № XXXI, 1876, pp. 247-248. (Relato).

327. "Los celos". № XXXIV, 1876, pp. 271-272. (Artículo).

C.G. DE B.

328. "Un tipo limeño", № XLIX, 1876, p. 390. (Poesía).

CABELLO, Gerardo

329. "Reflexiones sobre la situación política y económica del Perú". № XXXII, 1877, pp. 249-250. (Artículo).

CABELLO DE CARBONERA, Mercedes (Moquegua, 1845-1909).

330. "Influencia de la mujer en la civilización". Número Extraordinario, 1874, Tomo IV, p. XXVI. (Artículo).

331. "En la tumba de mi hermano". № XLIV, 1875, p. 355. (Poesía).

332. "La poesía". Número Extraordinario, 1875, Tomo V, p. XVII. (Artículo).

333. "La lectura" $\cdot N^{2}$ I, 1876, pp. 1-2. (Artículo).

334. "Patriotismo de 1a mujer". № XX, 1876, pp. 154-156. [Discurso pronunciado eñ â fiestá dê 'Club Literario' con motivo del 2 de mayo].

335. "La mujer y la doctrina materialista". $\mathrm{N}^{2} \mathrm{XI}, 1877$, pp. [81]-82. (Artículo).

336. "Meditaciones literarias". № XV, 1877, pp. 115-116. (Artículo).

CÁCERES PRAT, Acacio

337. La lámpara y la vieja. № XXII, 1876, p. 174. (Poesía).

\section{CAGLIOSTRO}

338. "El telégrafo de nácar". № 5, 1871, p. 35. /Se refiere al abanico. Vide: Grabado/ (Artículo).

339. "Ambición". № 7, 1871, p. [49]. (Artículo).

340. "El doctor Manuel Cardoso". № 10, 1871, p. 71 [En la muerte del distinguido abogado de la Corte de Trujillo] (Artículo). 
341. “La hipocresía política". № 11, 1871, pp. [79]. (Artículo).

CALCAÑo, José Antonio

342. "Los dos leños". No XXV, 1874, p. 196. (Poesía).

343. "La siega". № XXVII, 1874, p. 210. (Poesía).

344. "La tradición sobre Safo". № LI, 1874, p. 406. [Carta de respuesta al Sr. Don Enrique Piñeyro por el envío de la revista Mundo Nuevo].

345. "El telescopio". № III, 1875, p. 20. (Relato).

346. "En un cementerio". N I, 1875, p. 5 (Poesía).

347. "A dos señoritas residentes en New York". № XLI, 1875, p. 328. (Poesía).

348. "La cadena y el laúd”. № XXII, 1876, p. 174. (Poesía).

349. "Rafael y Fortunata". N² XLV, 1876, pp. 358-359. (Poesía).

350. "Rafael y la Fornarina". № XLVI, 1876, pp. 362-363. (Poesía).

351. "Ya vuelven los pescadores". № XL, 1877, p. 318. (Poesía).

CALDERA, Daniel

352. "Ven a gozar". № XXXII, 1874, pp. 253-254. (Poesía).

253. "Je T"aime". № III, 1875, p. 19. (Poesía).

354. "El puente". № III, 1875, p. 19. (Poesía).

355. "A Lisi". № IV, 1875, pp. 29-30. (Poesía).

356. "En la playa”, № XVII, 1876, po142. (Poesía).

CALISTO POMPA, Elías

357. "Pensando en ti”. № VI, 1876, p. 42. (Poesía).

CALLE, A. Belisario

358. "La caída de las hojas". № XXVIII, 1874, p. 218. (Poesía).

359. "La soberbia”. № XLIII, 1874, p. 342. (Artículo).

360. "Ella”. № XLVI, 1874, p. 365. (Poesía).

361. "Los trozos de la serpiente". № XII, 1876, p. 96. (Poesía).

362. "Biografía de Melgar". N XLVIII, 1876, pp. 381-382. [Rasgos biográficos].

363. Ídem. $\mathrm{N}^{2}$ XLIX, 1876, pp. 388-389.

CAMACHO, Juan Vicente (Venezolano, 1829-1872)

364. "En un álbum". Número Extraordinario, 1873, Tomo III, p. XXVIII. (Poesía). 
365. "A Rosa". $N^{2}$ XLVII, 1874, p. 375. (Poesía).

366. "N'ell mezzo del cammin di nostra vita..." Número Extraordinario, 1874, Tomo IV, p. XXXII, /Traducción de la obra de Dante/ (Poesía).

367. "Un banquero como hay pocos". № LI, 1875, pp. 410-412. (Poesía).

368. "Los polvos". Número Extraordinario, 1875, Tomo V, pp. XXIIXXIII. (Artículo).

369. "La hora de la desgracia". $N^{2} \mathrm{XXV}, 1876$, p. 199. (Prosa poética).

370. "A mi hijita de cinco años". № XXV, 1877, p. 196. (Poesía).

371. "Un soneto inédito". № XXXIX, 1877, p. 307. (Poesía).

\section{CAMAGÜEYANO}

372. "A la gloriosa muerte del ciudadano Luis Ayestarán". № XXXVII, 1872, p. 292. (Poesía).

CAMPASAS, Fray Gerundio de

373. "El diablo de la política". Primera tentación. N XV, 1873, p. 118. (Artículo).

374. İdem, № XVII, 1873 , p. 133. (Artículo).

375. Ídem, № XVIII, 1873, pp. 140-141. (Artículo).

376. Ídem, $\mathrm{N}^{2} \mathrm{XIX}, 1873$, p. 150. (Artículo).

377. “¡Si fueracierto!”。 № XXI, 1873 ppp.164-165. (Artículo).

378. "Mi miedo". NQ XXII, 1872 pp. 174-175. (Artículo).

379. "El diablo de la política". N" XXVI, 1873, pp. 206-207. (Artículo).

CAMPOAMOR, R[amón] de, (Español, 1817-1901)

380. "El trompo y la muñeca". № X, 1876, p. 75-76. (Poesía).

381. "El mayor castigo". № XV, 1877, p. 117. (Poesía).

382. "La música". № XVI, 1877, pp. 123-124. (Poesía).

383. "Los dos espejos". № XVIII, 1877, p. 143. (Poesía).

384. "Dichas sin nombre". N XIX, 1877, pp. 149-150. (Poesía).

385. “Contrastes". № XX, 1877, p. 156. (Poesía).

386. "Mal de muchas". № XL, 1877, p. [313]. (Poesía).

386. "La confesión de Florinda". № XLII, 1877, p. 336. (Poesía).

CAMPOS, D.

387. "Carolina Freyre de Jaimes". NN XLI, 1875, p. [325]. (Poesía).

388. "En la tumba de Vijil”. № XLIII, 1875, p. 342. (Poesía). 
CANDIA, Pedro de, (Seud.?)

389. "La estafeta". № VII, 1874, p. 51. (Artículo).

390. "Entre dos años". № VIII, 1874, p. 59. [Artículo sobre el quehacer literario de Ricardo Rossel].

391. "Un paralelo social”. N ${ }^{2} \mathrm{XI}, 1874$, pp. 83-84. (Artículo).

CANO, Baldomero

392. “Un beso". № XXXV, 1873, p. 282. (Poesía).

CARBONERO Y SOL, León (Traductor)

393. "El caballo". № XXXV, 1876, p. 280. (Poesía árabe).

CÁRDENAS

394. "Crisis de numerario". № XXVI, 1873, p. 203. (Artículo).

CÁRDENAS, J.M.

395. "Sociedades anónimas" Número Extraordinario, 1873, Tomo III, pp. VI-VII. (Artículo).

CARLOS

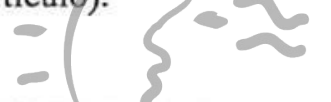

396. “Actualidad”. № XXII, 1874, p. 171. (Poesía).

CARMONA, Manuel Guillermo

397. "Francisco-dePaula-Taforo" $\mathrm{N}^{2} 2 \mathrm{f}$, 2a.epoca 1878, pp. 166-167. [Rasgos biograficos].ccinelli Converso"

CARNICER, Francisco

398. "Del plajio y de los plajiarios en Literatura [sic]". № I, 1876, p.

7. (Artículo).

CARO, J.E.

399. “Ceniza y llanto". № III, 1875, p. 23. (Poesía).

CARO, M.A.

400. "Respeto a la desgracia". № XVII, 1878, p. 135. (Poesía).

401. “Córcega”. № XVII, 1878, p. 135. (Poesía). 
CARPIO, Manuel

402. "La virgen al pie de la cruz". № XXIV, 1876, pp. 189-190. (Poesía).

CARRASCO, Constantino (1841-1877)

403. "A mi amigo don Trinidad Fernández". № 7, 1871, p. 53. (Poesía).

404. "Al Inca Garcilaso". № XXII, 1872, p. 174. (Poesía).

405. "Carta a mi hermana Aurora". NㅗXXVII, 1872, pp. 211-212. (Poesía).

406. "La Helena del Zeuxis". N XI, 1873, p. 86. (Poesía).

407. "Colón". N² XII, 1873, p. 95. (Poesía).

408. "Ay de mí". $\mathrm{N}^{2}$ XVII, 1873, p. 134. (Poesía).

409. "Llanto de amistad". № XIX, 1873, p. 150. (Poesía).

410. “¿Cuál de las dos?”. № XIX, 1873, p. 151. (Poesía).

411. "Las mujeres y el sol". № XXI, 1873, p. 167. (Poesía).

412. "Epicedio de Camila". № XXIII, 1873, pp. 182-183. (Poesía).

413. "Epitafios". № XXVII, 1873, p. 214. (Poesía).

414. "Pachacamac". Ne XXIX, 1873, p- 231. (Poesía).

415. “A la bandera peruana”. NN XXXIII, 1873, pp. 265-266. (Poesía). 416. “A la Sra. García Rodríguez. № XXXIII, 1873, p. 266. (Poesía). 417. "A la Luna”. № XXXV, 1873, p. 282. (Poesía).

418. "La expulsión de los jesuitas". № XXXVI, 1873, pp. 289-291. (Romancepopoullar inédito; refundido parasEl Correo del Perú por C.C.).

419. "Epigramas". N XLI, 1873, p. 330. (Poesía).

420. "Al colocar la lápida del sepulcro de la niña Rosa-Aurora Espinoza". № XLV, 1873, p. 363. (Poesía).

421. "El busto de nieve". № XLVII, 1873, p. 378. (Poesía).

422. "Maldición a la lira". Número Extraordinario, 1873, Tomo III, p. XVII. (Poesía).

423. "En la muerte de María, mi nodriza". № V, 1874, p. 39. (Poesía).

424. "Sonetos". № XI, 1874, p. 85. (Poesías) /Traducciones/

425. "Las dos muertes". № XII, 1874, p. 94. (Poesía).

426. "Al Rímac". № XIV, 1874, p. 110 . (Poesía).

427. "A un amancae". N $N^{\mathrm{X} X}, 1874$, p. 156. (Poesía).

428. "A un poeta". № XVIII, 1874, p. 140. (Poesía).

429. "El placer de la memoria". $\mathrm{N}^{2} \mathrm{XXI}, 1874$, p. 164. (Poesía).

430. “La victoria de Junín”. № XXX, 1874, p. 234. (Poesía). 
431. "Irregularidades del idioma castellano". Ortografía. N XXXIV, 1874, pp. 267-268. (Artículo).

432. "A Felicia". N XXXIX, 1874, p. 306. (Poesía).

433. "Enrique Seoane". № LI, 1874, p. 404. [Pincelada biográfica de C.C. a la muerte de su primo E. Seoane, autor de la novela por entregas, Mica la loca].

434. "A Raimondi". Número Extraordinario, 1874, p. XXXI. (Poesía).

435. "La vida y la muerte". $N^{2}$ XVIII, 1875, p. 144. (Artículo).

436. "A Dalmiro". № XX, 1875, p. 164. (Poesía).

437. "A una madre en la muerte de su hijo". $N^{2}$ I, 1875, pp. 2-3. (Poesía).

438. "El rapto de Proserpina". № XXXV, 1875, p. 278. (Artículo).

439. "Ollanta. Drama quichua en tres actos y en verso". $\mathrm{N}^{2}$ XXXVII, 1875, pp. 295-297. (Artículo).

440. Ídem. $\mathrm{N}^{2}$ XXXVIII, 1975, pp. 304. 306.

441. Ídem. $\mathrm{N}^{2}$ XXXIX, $1875,312-313$.

442. Ídem. $\mathrm{N}^{\circ}$ XLV, 1875 , pp. 358-360. (A José S. Barranca).

443. Ídem. № XLVI, 1875 , pp 367-368.

444. Ídem. $\mathrm{N}^{2}$ XLVIII, 1875 , pp. 385-386.

445. Ídem. № XLIX, 1875, pp. 391-393.

446. "El árbol de la quina”. Número Extraordinario, 1875, Tomo V, pp. XXXV-XXXVI. (A Juan de Arona). [Sobre este poema Menéndez y Pelayo]

447. "En la muerte del señor Santiago Flores". № VIII, 1876, p. 61. (Poesía).

448. "Regreso a la patria". No XVIII, 1876, pp. 139-140. /A don Guillermo Seoane/ (Poesía).

449. "Respuesta a Dalmiro". № XXXIV, 1876, p. 266. (Poesía).

450. “Consuelo". № XXXV, 1876, p. 280. /A Juan de Arona/ (Poesía). 451. "A la señorita Manuela Carrillo". N XL, 1876, p. 319. (Poesía).

452. "Nueve de diciembre". $N^{2}$ L, 1876, p. 400. /Al Coronel Manuel Odriozola/ (Poesía).

453. "A la señora". $\mathrm{N}^{2}$ VIII, 1877, p. 64. (Poesía).

454. "A Manuel María Flores". № X, 1877, pp. 75. (Poesía).

455. “El Dr. D. Antonio Raimondi”. № XI, 1877, pp. 85-86. [Rasgos biográficos].

456. “Ollanta". № XLVII, 1877, pp. 375-376. /A José S. Barranca primer traductor de este drama/. 
CARRIÓN, M.R.

457. "Aritmética". № XXXIII, 1875, p. 268. (Poesía).

CASÓS, Fernando (Trujillo, 1828-1882)

458. "La democracia y sus derechos de la América Latina". Número Extraordinario, 1872, p. XV. (Artículo).

CASTILLO, Manuel (Arequipa, 1814-1871)

459. "Buen consejo". № XVI, 1876, p. 124. (Poesía).

460. "Resurrección del sentimiento". № XXXVII, 1877, pp. 292-293. (Poesía).

CASTRO, Adolfo de

461. “Un obispo poeta”. № XVI, 1876, pp. 121-122. [Artículo sobre el obispo de Cuenca el Dr. Sebastián Herrero y Espinoza de los Monteros, Arcipreste de la Santa Iglesia Catedral de Cádiz].

CATALINA; Severo

462. "A una niña". N ${ }^{2}$ XIII, 1874, p. 101. (Poesía).

463. "Décima”. NN XIV, 1874, p. 110 (Poesía).

464. "Décima". No XVII, 1874, p. 134. (Poesía).

CATORCENERO (El) Biblioteca de Tetras

465. "A Chavot" $\mathrm{N}^{2}$ XXIV 1876; P. [185] (Poesía).

CAZENEUVE, Felipe Gerardo

466. Realidad y ficción. $\mathrm{N}^{2}$ XXXVII, 1872, pp. 293-294. (Relato).

467. Bálsamo del alma. $\mathrm{N}^{2}$ VIII, 1874, p. 62. (Artículo).

CAZURRO, M.Z.

468. "El aire más fresco". N² XLVII, 1874, p. 373. (Poesía).

CÉSAR

469. "El capitán Araña". № XXVIII, 1875, p. 228. (Historia de un refrán) [sic].

470. Ídem, $\mathrm{N}^{2}$ XXVI, 1877, pp. 206-207. (Artículo). 
CISNEROS, Luis B[enjamín] (1837-1904)

471. "En la pampa". Número Extraordinario, 1873, Tomo III, p. X. (Artículo).

472. “Cecilia”. № VI, 1875, pp. 42-43. (Relato).

473. "La medalla de un libertador". Número Extraordinario, 1875, Tomo V, pp. XLII-XLIII. (Relato).

CLÉMENT, M.A.

474. Vide: OSCAR. "Investigaciones sobre las causas de la indigencia".

COBO, Camilo $\mathrm{H}$.

475. "Adela". № IV, 1876, p. 29. (Poesía).

476. “La guinda”. № V, 1876, p. 39. (Poesía).

COELLO, Carlos

477. "Fábulas". № XLII, 1875, p. 335.

COLUNGE, Angel Enrique

478. "[Antigüedades Peruanas]". NeV,1874, p. 39. (Informe ante el Sr. Juez de Primera Instancia).

CONCHA, Clodomiro

479. "Verdades para unos mentiras para otros". № XIX, 1875, p. 151. (Artículo humorístico).

480. "Un matrimonio despuese de muefto" 9 Ne VI, 1875, pp. 44-45. (Relato.

481. "La felicidad del pobre". N XI, 1875, p. 86. (Artículo).

482. "El barranco de los aparecidos". № XII, 1875, pp. 94-95. (Tradición).

483. "La tumba y el esqueleto". № XIV, 1875, pp. 110-111. (Relato).

484. "De cómo se calumnia al diablo". Número Extraordinario, 1875, Tomo V, pp. XXIV-XXV. (Tradición).

485. "Una emplumada". № XXXIII, 1874, pp. 260-261. (Artículo).

486. "Milagros de un santo". № XLVII, 1874, pp. 373-375. (Tradición).

487. "El cura Monardes". № XV, pp. 116-118. (Tradición).

488. “Un cura vencido por un lego". № XIX, 1875, pp. 146-147. (Relato).

489. "Las limeñas sin medias". N II, 1875, pp. 13-14. (Tradición). 
490. "El clérigo Morán y la Convención Francesa". № XXVIII, 1875, pp. 223-225. (Tradición).

491. “Cómo se perdonaban los pecados en el siglo XVII”. № XXXVIII, 1875, pp. 307-108. (Tradición).

492. "Milagros de Fray Jorge". № XLVII, 1875, pp. 378-380. (Artículo histórico tradicional).

493. "Las costumbres y sus consecuencias". NN XLIX, 1875, pp. 393394. (Artículo).

494. "Argumento para un drama". № LI, 1875, pp. 408-409. (Relato).

495. "La capa de antaño". Número Extraordinario, 1875, Tomo V, p. XIX. (Artículo).

496. "Amor sin interés". № I, 1876, pp. 5-6. (Tradición).

497. "Un gran acontecimiento". $\mathrm{N}^{2} \mathrm{~V}, 1876$, pp. 36-38. (Tradición).

498. "Un prometido desgraciado". $N^{2}$ VII, 1876, pp. 46-47. (Tradición).

499. "Origen de un refrán". Como se paga se canta. № XII, 1876, p. 95. (Artículo).

500. "En busca de una princesa". № XIV, 1876, pp. 110-111. (A R. Palma). (Tradición)

501. "Una maldición". № XXI, 1876, pp. 172-174. (Relato).

502. "Predestinación". N N XXIII, 1876, pp. 181-182. (Relato).

503. "De cómo se estableció en América el estancio". № XXVII, 1876, pp. 213-214. (Tradición).

504. "Una venganza de la-sociedad”, № XXXI, 1876, p. 253. (Relato). 505. "Lucha desigual". $\mathrm{N}^{2}$ XXXII 1876, pp. 262-263. (Tradición).

501. Ídem. № XXX1V, 1876, pp. 267-268. (Tradición).

502. "La mujer y el matrimonio". № XLIII, 1876, p. 344. (Artículo).

503. "Un frayle que se alimentaba de cadáveres". № I, 1877, pp. 7-8. (Relato).

504. “No era lerdo el frayle [sic]". № IV, 1877, pp. 31-32. (Tradición). 505. “¡Al freír de los huevos lo veremos!”. N² XXXVII, 1877, pp. 294295. (Relato).

506. “A arrear borricos”. № XXXVIII, 1877, pp. 303-304. (Relato). 507. "Justicia seca". № XLI, 1877, p. 327. (Artículo).

CONDEMARÍN, J.D.

508. "La mano suave y los mostachos". $\mathrm{N}^{2} \mathrm{XL}, 1877$, p. 320. /A Ricardo Palma/ (Tradición). 
CONDE DE FUENTE-HERMOSA

509. "Fantasía". № XXXVII, 1873, p. 298. (Poesía).

510. “A mi sobrino Julio". N ${ }^{2}$ XLII, 1873, p. 339. (Poesía).

511. “A..." № XLVII, 1873, p. 378. (Poesía).

512. "A mi amigo don Alejandro C. Rodríguez con motivo de la sentida muerte de su hija Armantina". № IV, 1874, p. 30. (Poesía).

513. "Tristeza". № XI, 1874, p. 86. (Poesía).

514. "A..." No XV, 1874, p. 118. (Poesía).

515. "Un recuerdo a María". № XVIII, 1874, p. 142. (Prosa poética).

516. "Suspiros”. № XXII, 1874, p. 172. (Poesía).

CONDE ROSELL Y DE LORGUES (El)

517. "Los dos sepulcros de Colón”. № XII, 1878, pp. 92-93. (Artículo).

CONDE DE SANTIAGO (El)

518. “César”. № XXIX, 1874, p. 226. (Poesía).

COOD, Enrique

519. "Gramática teórico-práctica de la lengua castellana". № XLVI, 1877, pp. 366-367. (Artículo).

CORDERO, César A.

520. "Emancipación social y civil de la mujer". № XLII, 1876, pp. $335-$ 336. (Artículo).10teca de Letras

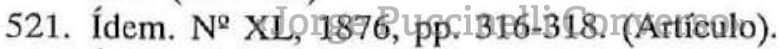

522. Ídem. $\mathrm{N}^{2} \mathrm{XLI}, 1876$, p. 325 . (Artículo).

CORDERO, Inocencio

523. "Soliloquio". № XXXII, 1873, pp. 256-257. (Artículo).

CÓRDOVA Y URRUTIA, J[osé] M[aría] (1806-1850)

524. “Antiguallas". $\mathrm{N}^{2} \mathrm{~L}, 1874$, pp. 394-395. (Lista de quiénes en el Perú compraron sus títulos de nobleza).

CORONADO, Martín

525. "Diálogo inmortal”. N XVI, 1876, p. 128. (Poesía).

CORONADO, Vicente

526. "El cóndor". № L, 1876, p. 400. (Artículo). 
CORNEJO, Antonio

527. “Los niños y el rosal”. № XL, 1874, p. 318. (Poesía).

CORPANCHO, Teobaldo Elías (1852-1930)

528. "Armonía universal". N² XLIII, 1873, p. 346. (Poesía).

529. “A Cristina Bustamante en su álbum”. № III, 1874, p. 23. (Poesía).

530. "La última noche". $\mathrm{N}^{2} \mathrm{III}, 1874$, pp. 22-23. (Poesía).

531. "Al general Prado en recuerdo de sus glorias". № XLVIII, 1874, p. 378. (Poesía).

532. "En la glorieta". Número Extraordinario, 1874, Tomo IV, p. XXXI. (Poesía).

533. "La ofrenda del poeta". Número Extraordinario, 1875, Tomo V, p. XV. (Poesía).

534. “Glorias que fueron”. № I, 1877, p. 76. (Poesía).

CORTÉS, María Natividad

535. "Esperanza". № XVLI, 1875, p. 143. (Poesía).

536. "A una niña”. Número Extraorđinario, 1875, Tomo V, pp. XXXIVXXXV. (Poesía).

CORZUELO, A.

537. "Mi amigo". X. $\mathrm{N}^{2} \mathrm{XLH}, 1874$, p. 331. (Relato).

CORRALES, Enrique

\section{Biblioteca de Letras}

538. "La primera cana". N2 XVII, 1877, p. 131. (Poesía).

CORREO DEL PERÚ (El)

539. "Charada". № XLVIII, 1874, p. 384.

COSMES, Francisco G.

540. "El poeta". № XVII, 1876, p. 136. (Poesía).

COTERA

541. "Línea de vapores entre el Perú y el Asia". № XVI, 1877, pp. 124125. (Artículo).

CRESCENTE ERRAZURIS

542. "Cómo llega a creerse una fábula absurda". № XXII, 1877, pp. 174-175. (Artículo). 
CRESPO, C.S.

543. "Propósitos de borrachos". N XLIII, 1874, pp. 343-344. (Poema humorístico).

CRUZAT, Federico

544. "La cautiva solitaria". $N^{2}$ IV, 1876, p. 28. (Poesía).

545. "En el mar". N XVII, 1877, pp. 133-134. (Poesía).

546. "Un beso". № XXII, 1876, p. 176. (Poesía).

CUADRA, Fernando

547. "A la heroica Cuba". № II, 1874, pp. 14-15. [Con motivo del fusilamiento del general Varona, Ryan, Céspedes y Jesús del Sol. Dedicada a los cubanos residentes en el Perú]. (Poesía).

\section{CUCUFATO}

548. "Las abuelas". № XXXVII, 1876, pp. 290-292. (Relato).

549. "Mi amiga Bartola". № XXXIX, 1876, pp. 308-309. (Relato).

550. "Cupido y un inglés". № XL, 1876, pp. 314-316. (Relato).

551. "Carta marítima amorosa". N² LI, 1876, p. 411.

552. "Reminiscencias de París". № IV, 1877, p. 31. (Relato).

553. "Las suegras". № XVII, 1878, pp. 134-135. (Artículo humorísti$\mathrm{co})$.

cueto, Manuel Biblioteca de Letras

554. "A un envidioso"P Neđin 4874, p. 398s (Poesía).

CUEVA, Mariano

555. "Dolores Veintimilla". № XXXVIII, 1874, p. 299. [Tomado de Nueva Era, publicación de Guayaquil] (Artículo).

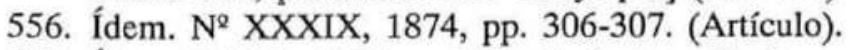

557. Ídem. $\mathrm{N}^{2} \mathrm{XL}, 1874$, p. 319. (Artículo crítico).

558. Ídem. $\mathrm{N}^{2} \mathrm{XLI}, 1874$, pp. 323-324. (Artículo crítico). 